information to pyramidal and extrapyramidal motor systems through the neostriatum. Grafted striatal cells can reconstruct precise afferent and efferent connections with the host brain, and provide the basis for recovery in both spontaneous and complex behaviours'. Although the time-course of regrowth and functional recovery in animals with striatal grafts has not been studied as systematically as the present observations on cerebellar grafts in the $p c d$ mouse, the full extent of striatal regeneration in adult hosts is extended over a period of months, rather than taking place within the restricted timeframe that applies to the ontogenetic development of these connections.

How can these different perspectives be resolved? There is growing realization that grafted neuronal cells can exert a functional influence over the host brain by various mechanisms, from the acute release of growth and trophic factors into the damaged host central nervous system, through the chronic secretion of deficient neurochemicals (the paracrine model) and the tonic reinnervation of the host brain, to reciprocal axonal growth and reformation of synaptic connections between the neurons of the graft and host brain $^{6}$. The extent to which a particular degree of appropriate structural and functional integration takes place depends not only on the model system, but also on the lesion and other growth-promoting events in the host brain, the developmental age, placement and constituents of the graft, and the particular set of connections under investigation. The identification and characterization of the factors influencing the extent of anatomical reconstruction and the mechanisms of function of neural grafts is a topic of active research interest in several laboratories. The observations by Sotelo and AlvardoMallart indicate the extent and precision of structural reconstruction that can take place under favourable circumstances.

1. Snyder, S.H. Nature 326, 824-825 (1987).

2. Sotelo, C. \& Alvardo-Mallart, R.M. Nature 327, 421-423 (1987).

3. Sotelo, C. \& Alvardo-Mallart, R.M. Neuroscience 20, 1.22 (1987).

4. Björklund, A. \& Gage. F.H. Ann. N.Y. Acad. Sci. 457, 53 81 (1986)

5. Isacson, O., Dunnett, S.B. \& Björklund, A. Proc. natn Acad. Sci. U.S.A. 83, 2728-2732 (1986).

6. Björklund, A. et al. Trends Neurosci. (in the press).

Stephen B. Dunnett is in the Department of Experimental Psychology, University of Cambridge, Cambridge CB2 3EB, UK.

\title{
Environmental ecology
}

\section{Unforeseen effects of control}

\section{Malcolm Coe}

IN our haste to reduce the effects of pests and diseases on the secondary production of our domestic stock, we are often less informed than we should be about the broader ecological consequences of such new methods of treatment and control. Wall and Strong, on page 418 of this issue ${ }^{1}$, draw our attention to the potential dangers of using the anti-parasitic drug invermectin, not because of its effect on the large herbivores themselves, but because of the much less obvious, but vitally important, detritivore community associated with their dung.

Ever since the first terrestrial herbivores evolved, their faeces have provided a valuable source of food for various invertebrates, many of which are dung specialists. Predominant among this diverse fauna are the 14,000 species of dung beetle (Family Scarabaeidae). These insects have evolved a high degree of sociality in the care of their eggs and larvae, which complete their development in dung or broodballs that can be located in the dung source or in an underground brood-chamber. These beetles, which range in mass from $19 \mathrm{~g}$ (Heliocopris dilloni) to $0.004 \mathrm{~g}$ (Drepanocereus parallelus $)^{2}$ are found throughout the world and are important removal agents of both herbivore and carnivore dung (see elephant dung in $2 \mathrm{~h}$, during which time all the soft edible material had either been eaten in situ, rolled up to $220 \mathrm{~m}$ away from the deposit or buried below it. This rapid mode of removal underlines the ecological importance of coprophagous insects in incorporating this digested plant litter into the soil, where much of it is decomposed by bacteria and fungi and its nutrients released for future plant growth. In addition to simply removing dung from the immediate soil surface, the burrowing activity, especially in arid to semi-arid environments, is of considerable significance in soil aeration, enhanced water percolation and in elevating up to $4 \mathrm{~kg}$ of soil to the surface for every kilogram (fresh weight) of elephant dung deposited in East Africa ${ }^{4}$.

Australian biologists realized the significance of dung-beetle activity when they observed that their endemic species were only adapted to the pelleted dung of herbivorous marsupials and were incapable of removing the dung deposited by introduced cattle. This dung in consequence persisted on the ground for long periods, suppressing grass production and providing breeding foci for flies. Since the mid-1960s CSIRO entomologists have carried out an extensive research programme in which they have introduced a range of dung-beetle species from Africa and elsewhere. These species have established themselves in many areas and have acted as efficient agents of dung removal, considerably reducing seasonal fly populations 5

Wall and Strong in this issue ${ }^{1}$ demonstrate that dung samples collected from calves fitted with rumenal boluses delivering invermectin at $40 \mu \mathrm{g}$ per $\mathrm{kg}$ per day contained a total of only 17 adult dung beetles, 35 dipterous larvae and 44 earthworms after 100 days, compared with controls, which yielded 780 dung beetles, 267 dipterous larvae and 46 earthworms over the same period. Although the authors correctly point out that these druginduced effects may vary with the manner in which the drug is administered, as well as with the geographical location and the climate, the ecological side-effects of such control methods need extensive study. Such influences on the local dung fauna could be particularly significant in developing countries where drug administration may be less stringent and the potential effects of dung removal and nutrient cycling catastrophic.

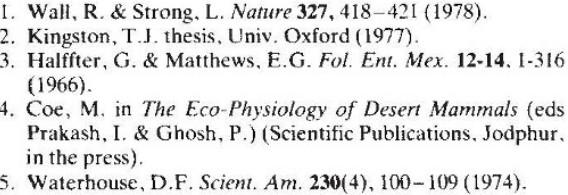

Malcolm Coe is in the Animal Ecology Research Group, Department of Zoology, University of Oxford, Oxford OXI 3PS, UK. 